\title{
Job Design, Training Effect and Job Satisfaction: Evidence from Work Placement at Audit Firms
}

\author{
Guangyou Liu* \\ Business School and Center for Accounting, Finance and Institutions, Sun Yat-sen University, \\ Guangzhou, 510275, P.R.China
}

\begin{abstract}
This paper aims to test the relationships between job design aspects and job satisfaction, as well as the mediating role of training effect in these relationships. Regression and mediation analyses were performed based on the data collected from a questionnaire-based survey on the senior accounting students' audit work placement at audit firms. I conclude that repeated tedious non-professional job aspect is negatively related to job satisfaction, whereas judgmental professional job aspect is positively related to job satisfaction. I also conclude that training effect of work placement is playing a partial mediating role in the identified positive relationship while having no mediation in the negative one.
\end{abstract}

\section{Introduction}

Work placement for accounting graduates is a critical stage for them to perceive as new experience to start their career development in the very near future. The work-integrated learning experience through work placement can help them shape the cognition of future public accounting profession. Particularly, job satisfaction during work placement will have critical impacts on the career decision facing these accounting students shortly before their graduation. In business education, work placement is becoming an important and effective learning tool for business students to bridge the gap between classroom learning and real world practices ${ }^{[1]}$. The term 'work placement' is equivalent to 'internship' and 'on-the-job training' used by other scholars. Maertz Jr. et al. suggest that successful internships can benefit the interns, schools and employers, and especially the need of students for experiential and vocational learning can be fulfilled ${ }^{[2]}$.

This paper aims to test the relationships between job design in work placement and job satisfaction, as well as the mediating role of training effect in these relationships, based on the data collected from a questionnaire-based survey was completed among a group of senior accounting students who had just finished their work placement at Audit firms. This study makes its unique contribution to the existing accounting education literature by applying the behavioural and cognitive perspectives such as job design, training effect and

\footnotetext{
*Corresponding author: mnslgy@mail.sysu.edu.cn
} 
job satisfaction in accounting research. My findings are implicative to accounting schools and audit firms in improving job training for their students and future employees.

\section{Some Institutional Features of Chinese Accounting Education}

At least three institutional features of the Chinese accounting university education offer a significant opportunity of studying Asian accounting education. First, China is the largest economy in Asia, fully representative of the emerging and transitory markets in the world. Second, there is an emerging and increasing demand for quality audit professionals in the course of rapid social and economic developments in China. Lastly, Chinese educational systems are similar to those in other Asian countries by sharing cultural values. The Chinese rapid economic growth in most recent four decades calls for the powerful support and safeguard from a well-educated auditing profession. The behavioural and cognitive aspects in accounting education and audit skills training are crucial to the formation of a well-functioning auditing profession in China. Liu points out that nowadays in the key Chinese universities that focus on the training effects of placing their accounting students in the field practices at audit firms, and that the work placement through internships is a compulsory part of the accounting schools' curriculum ${ }^{[3]}$. Pedagogically speaking, audit work placement via the university-and-audit-firm cooperative education programs not only helps students to enhance their understanding of the textbooks taught in the classroom, but also lays solid foundations for successful future professional careers ${ }^{[3]}$. This study focuses on job design in audit work placement and job satisfaction for the senior accounting students in the Chinese auditing professional context. Table 1 lists the common characteristics of audit work placement for the Chinese accounting students as summarized in comparisons with the job aspects described in the work of Maertz Jr. et al. ${ }^{[2]}$.

Table 1. Characteristics of Audit Work Placement for Accounting Students in China

\begin{tabular}{|l|l|}
\hline Dimension & Description of Work Placement Features \\
\hline Payment & Paid at the minimum wage level \\
\hline Time schedule & Full time work \\
\hline Participant & Undergraduate and professional internship \\
\hline Credit & Academic course credit \\
\hline Academic requirement & High formal academic requirements and on-the-job experiences \\
\hline Organizer & Arranged officially between intern-employer and school \\
\hline Internship duties & Well defined and well planned, not "do whatever is needed or asked" \\
\hline Work format & Project-based format, not job-based format \\
\hline Mentorship & Work sponsor and mentor (i.e. experienced CPAs in the audit firm) \\
\hline Future job opportunity & Implication regarding future bilateral job/recruitment opportunity \\
\hline
\end{tabular}

\section{Literature Review and Development of Research Hypotheses}

As it is widely accepted by both business researchers and practitioners, job design aspects and characteristics are significantly related to job satisfaction ${ }^{[4]}$. Although there are different ways to categorize job aspects, job design has been generally defined as designing task and role content of jobs to fit in the social and psychological needs of job takers ${ }^{[5]}$. Theoretically there shall be some associations between job design as work inputs and job satisfaction as social and cognitive outcomes.

Some scholars conclude that job aspects such as autonomy, variety and significance can increase positive impacts of job design on job performance and satisfaction ${ }^{[6]}{ }^{[7]}$. Others find that higher educated workers like university graduates are more satisfied with their jobs because they have a job of better quality, however, the association between the level of 
education and job satisfaction is negative for the first job ${ }^{[8]}$. Humphrey et al. criticize that most of the existing job satisfaction studies only focus on work aspects, ignoring social and contextual aspects of work ${ }^{[9]}$. To follow this criticism, I include in the regression model two team aspects as social contexts in addition to those job aspects. My research hypotheses on the relationships between job aspects and job satisfaction are presented in Figure 1.

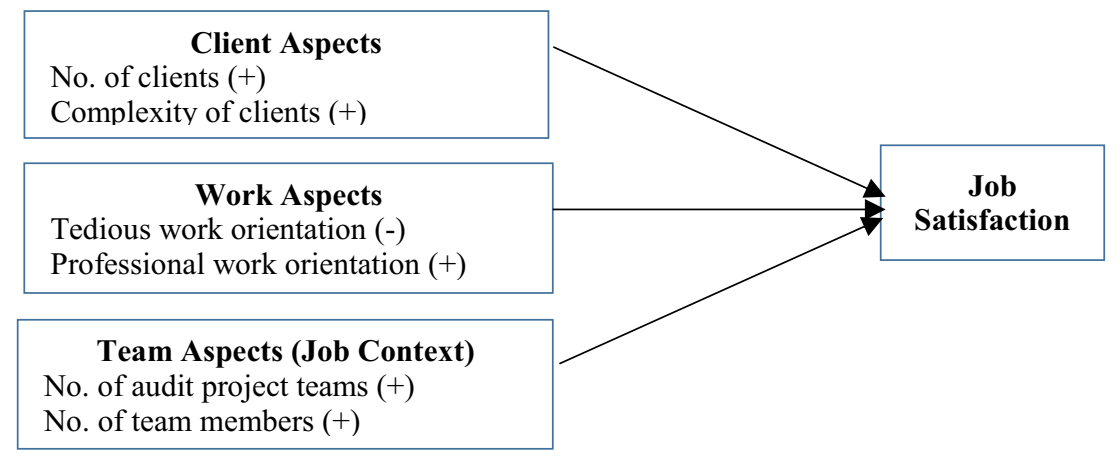

Figure 1 Hypotheses on Relationships between Job Design Features and Job Satisfaction

Further investigations concern how people are satisfied with their jobs. Some scholars prove that jobs with high problem-solving requirements increase job satisfaction because these job provide a chance of demonstrating and reinforcing the sense of professional and judgmental competence on the job ${ }^{[10][11]}$. Some studies emphasize the training effect. For example, Howard et al. conclude that the on-the-job training effect is especially important to motivate and satisfy the new entry-level professionals, and that a strongly motivated learner at workplace evaluates highly the change to learn new things and to extend the range of professional competencies ${ }^{[11]}$. To grasp these implications in prior literature regarding the impacts of on-the-job training effect, I conjecture that training effect may play the mediating role in the relationship between job aspects and job satisfaction. My related hypotheses are expressed by the SEM in Figure 2.

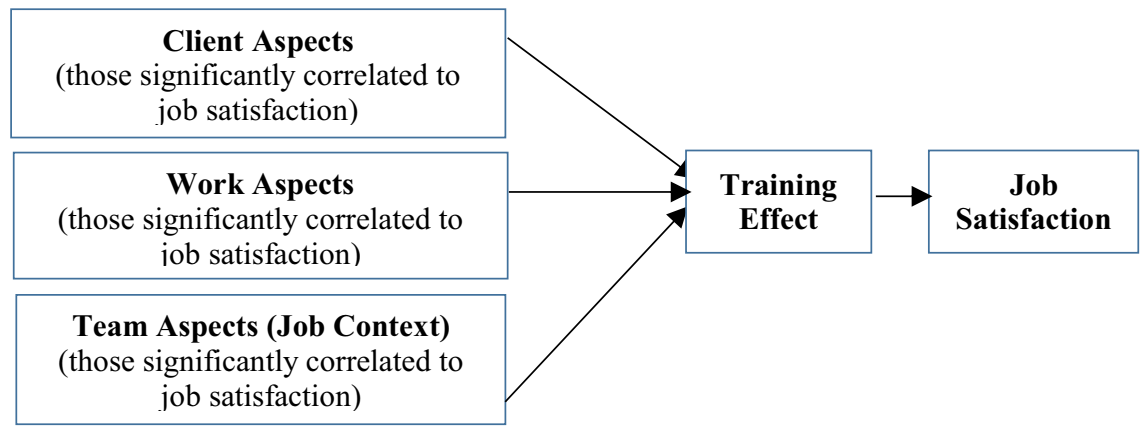

Figure 2 Hypotheses on Mediating Role of Training Effect

\section{Research Methodology}

\subsection{Data Collection}


The research data for this study have been collected from a two-year questionnaire-based survey on the cooperative accounting education arrangement in a top-tier Chinese university. The 30-minute surveys were administered anonymously in mid-May 2013 and 2014 respectively, among 350 interns in total who returned from the four-month work placement at Audit firms officially assigned by the university and 15 contracted Audit firms. 208 effective responses were collected. All the questionnaire items were either adapted from the existing literature or designed based on the interviews with 20 representatives from the target population who participated in a pilot pre-test before the formal surveys.

\subsection{Variables}

This study investigates four groups of variables, including dependent, explanatory, potential mediating, and control variables. Job satisfaction is the only dependent variable; six job design features of three dimensions are used as explanatory variables; gender and firm size are included in the regression model as control variables, and training effect is expected to be a mediating variable. Table 2 presents a summary of all the variables in this study.

Table 2. Variables and Descriptions

\begin{tabular}{|l|l|}
\hline Variable & Description \\
\hline SATISFACTION & Dependent variable indicating job satisfaction with work placement \\
\hline$T R E$ & Expected mediating variable indicating training effect of work placement \\
\hline$C L \_N O$ & Number of clients served during work placement \\
\hline$C L \_C M P L X$ & Degree of client complexity experienced in work placement \\
\hline$W K \_T E D I$ & Extent of repeating tedious non-professional jobs during work placement \\
\hline$W K \_P R O F$ & Extend of performing judgmental professional tasks during work placement \\
\hline$T M \_N O$ & Number of teams attended during work placment \\
\hline$T M \_P E E R S$ & Average number o peers on audit engagement teams \\
\hline GENDER & Control variable, indicating gender feature of questionnaire respondents \\
\hline FIRMSIZE & Control variable, indicating small, large and international Audit firms \\
\hline
\end{tabular}

\subsection{Testing Methods}

The testing methods used in this study include two parts. The following regression model is used to test the hypothesized relationships between job design aspects and job satisfaction, and a structural equation model (SEM) based on Figure 2 is used to test whether training effect mediate the proven significant relationship between job design and job satisfaction.

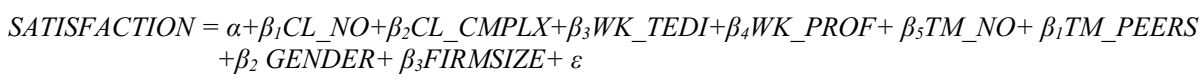

\section{Empirical Results and Analyses}

\subsection{Descriptive Statistics and Bivariate Correlation Analysis}

Tables 3 reports high job satisfaction (mean=4.99) and training effect (mean=5.26). It also shows the statistical characteristics of other variables under investigation.

Table 3. Descriptive Statistics

\begin{tabular}{|l|l|l|l|l|l|}
\hline Variable & N & Minimum & Maximum & Mean & St.Deviation \\
\hline
\end{tabular}




\begin{tabular}{|l|l|l|l|l|l|}
\hline SATISFACTION & 208 & 1.86 & 7.00 & 4.9918 & 1.00297 \\
\hline TRE & 208 & 2.44 & 7.00 & 5.2569 & .85275 \\
\hline$C L \_N O$ & 206 & .00 & 25.00 & 5.8641 & 4.70609 \\
\hline CL_CMPLX & 201 & .00 & 1.00 & .4174 & .34691 \\
\hline WK_TEDI & 208 & 1.30 & 7.00 & 4.8644 & 1.07253 \\
\hline WK_PROF & 208 & 1.00 & 7.00 & 3.8344 & 1.18299 \\
\hline TM_NO & 205 & 1 & 25 & 5.80 & 4.416 \\
\hline TM_PEERS & 204 & 2.0 & 48.0 & 7.030 & 5.0756 \\
\hline GENDER & 208 & 0 & 1 & .76 & .425 \\
\hline FIRMSIZE & 208 & 1.00 & 3.00 & 1.9087 & .64928 \\
\hline Valid N (Listwise $)$ & 198 & \multicolumn{5}{ll}{} \\
\hline
\end{tabular}

Table 4 reports the Pearson bivariate correlations between the studied variables. SATISFACTION is significantly associated with all the other variables except GENDER, while TRE is very significantly $(\mathrm{p}<0.01)$ correlated to $W K_{-} P R O F$ and FIRMSIZE. It can be preliminarily observed that job satisfaction is related to most job design aspects, and that only one job aspect WK_PROF is significantly correlated to job satisfaction.

Table 4. Pearson Bivariate Correlation Analysis

\begin{tabular}{|l|l|l|l|l|l|l|l|l|l|l|}
\hline Variable & $\mathbf{1}$ & $\mathbf{2}$ & $\mathbf{3}$ & $\mathbf{4}$ & $\mathbf{5}$ & $\mathbf{6}$ & $\mathbf{7}$ & $\mathbf{8}$ & $\mathbf{9}$ & $\mathbf{1 0}$ \\
\hline ISATISFACTION & 1 & & & & & & & & & \\
\hline $2 T R E$ & $.472^{* * *}$ & 1 & & & & & & & & \\
\hline $3 C L \_N O$ & $-.238^{* * *}$ & -.063 & 1 & & & & & & & \\
\hline $4 C L \_C M P L X$ & $.184^{* * *}$ & $.133^{*}$ & $-.331^{* * *}$ & 1 & & & & & & \\
\hline $5 W K \_T E D I$ & $-.207^{* * *}$ & .071 & $.237^{* * *}$ & -.011 & 1 & & & & & \\
\hline $6 W K \_P R O F$ & $.385^{* * *}$ & $.468^{* * *}$ & .014 & .014 & $.214^{* * *}$ & 1 & & & & \\
\hline $7 T M \_N O$ & $-.244^{* * *}$ & -.095 & $.805^{* * *}$ & $-.303^{* * *}$ & $.167^{* *}$ & -.034 & 1 & & & \\
\hline $8 T M \_P E E R S$ & $.196^{* * *}$ & .115 & $-.218^{* * *}$ & $.279^{* * *}$ & $-.218^{* * *}$ & -.051 & $-.250^{* * *}$ & 1 & & \\
\hline gGENDER & -.063 & .097 & .114 & .017 & $.122^{*}$ & .032 & .109 & -.051 & 1 & \\
\hline IOFIRMSIZE & $.497^{* * *}$ & $.263^{* * *}$ & $-.395^{* * *}$ & $.419^{* * *}$ & $-.164^{*}$ & $.240^{* * *}$ & $-.397^{* * *}$ & $.222^{* * *}$ & -.043 & 1 \\
\hline
\end{tabular}

Note: ${ }^{* * *} \mathrm{p}<0.01$ (2-tailed); ${ }^{* *} \mathrm{p}<0.05 ;{ }^{*} \mathrm{p}<0.10$.

\subsection{Tests on the Correlations between Job Design and Job Satisfaction}

Table 5 reports the regression results. The empirical results prove that tedious nonprofessional tasks are negatively correlated to job satisfaction $(\mathrm{p}<0.01)$, whereas correlation between judgmental professional tasks and job satisfaction is positive $(\mathrm{p}<0.01)$. No other variables significantly contribute to job satisfaction except for FIRMSIZE.

Table 5. Results of Regression on Job Satisfaction

\begin{tabular}{|c|c|c|c|}
\hline \multirow{2}{*}{$\begin{array}{l}\text { Explanatory } \\
\text { Variables }\end{array}$} & \multicolumn{3}{|c|}{ Standardized Coefficient } \\
\hline & Beta & $\mathbf{t}$ & Sig. \\
\hline (constant) & & 9.370 & .000 \\
\hline$C L \_N O$ & -.020 & -.189 & .850 \\
\hline CL_CMPLX & -.011 & -.170 & .865 \\
\hline WK_TEDI & -.207 & $-3.309^{* * *}$ & .001 \\
\hline WK_PROF & .318 & $5.127^{* * *}$ & .000 \\
\hline$T M \_N O$ & -.003 & -.025 & .980 \\
\hline TM_PEERS & .084 & 1.358 & .176 \\
\hline GENDER & -.018 & -.305 & .760 \\
\hline FIRMSIZE & .375 & $5.240^{* * *}$ & .000 \\
\hline
\end{tabular}




\begin{tabular}{|l|cccccc|}
\hline Model Summary \& & $\mathbf{R}$ & $\mathbf{R}^{\mathbf{2}}$ & $\mathbf{A d j} . \mathbf{R}^{2}$ & S.E. & $\mathbf{F}$ & Sig. \\
& .616 & .380 & .353 & .81306 & 14.455 & .000 \\
\hline
\end{tabular}

Note: ${ }^{* * *} \mathrm{p}<0.01$ (2-tailed); ${ }^{* *} \mathrm{p}<0.05 ;{ }^{*} \mathrm{p}<0.10$.

\subsection{Tests on the Mediating Role of Training Effect at Work Placement}

As it is indicated in Table 5 that among those explanatory variables, only $W K$ TEDI and WK_PROF have significant correlation with SATISFACTION, structural equation modeling is run on these two variables. Figure 3 describes the SEM results of the conceptual modelling on the potential mediating role of training effect. A significant $(\mathrm{p}<0.01)$ partial mediating function of TRE exists in the relationship between WK_PROF and SATISFACTION, not in that between WK_TEDI and SATISFACTION. These results lead to the conclusion that training effect plays a significant mediating role only in the relationship between judgmental professional tasks and job satisfaction, not in that between tedious non-professional tasks and job satisfaction.

Note further that the mediating function of TRE is partial, which means that the judgmental professional job aspect significantly increases job satisfaction and good on-thejob training effect in work placement is enhancing this increase.

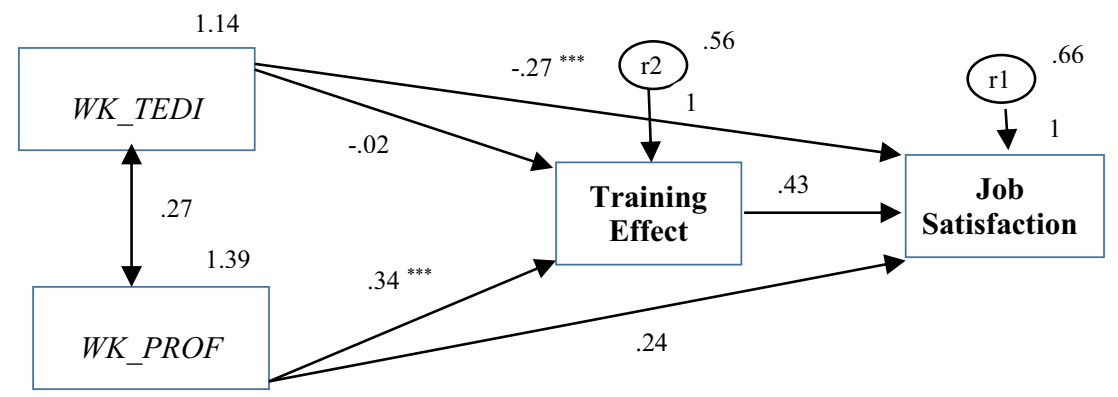

Figure 3 SEM Results regarding Mediating Role of Training Effect

\section{Conclusions and Implications}

The conclusions of this study include two parts. First, tedious non-professional tasks in work placement decrease job satisfaction, whereas judgmental professional tasks increase job satisfaction. Second, the partial mediating role of training effect significantly enhances the relationship between judgmental professional tasks and job satisfaction, in other words, if more judgment professional tasks were given, they could improve the training effect of work placemen, and eventually better job satisfaction.

My conclusions are quite implicative to accounting schools and audit firms, suggesting that students trained in audit work placement be given more judgmental professional tasks, which would lead to improvement in training effect and job satisfaction.

\section{References}

1. C.P., D'Abate, M.A., Youndt, K.E.Wenzel, Making the most of an internship: An empirical study of internship satisfaction. Academy of Management: Learning and Education, 8, 4 (2009). 
2. C.P., Maertz Jr., P.A., Stoeberl, J., Marks, Building successful internships: Lessons from the research for interns, schools, and employers. Career Development International, 19, 1 (2014).

3. G., Liu, A survey on student satisfaction with cooperative accounting education based on Audit firm internships. Asian Review of Accounting, 20, 3 (2012).

4. S., Mills, Job design. Personal Review, 2, 2 (1973).

5. J.R., Hackman, G.R., Oldham, Motivation through the design of work: Test of a theory. Organizational Behavior and Human Performance, 16, (1976).

6. Y., Fried, G. R., Ferris, The validity of the job characteristics model: A review and meta-analysis. Personnel Psychology, 40, (1987).

7. J., Sutherland, Employment status and job satisfaction. Evidence-based HRM: a Global Forum for Empirical Scholarship, 1, 2 (2013).

8. E., Verhofstad, H., De Witte, E. Omey, Higher educated workers: Better job but less satisfied? International Journal of Manpower, 28, 2 (2007).

9. S.E., Humphrey, J.D., Nahrgang, F.P. Morgeson, Integrating motivational, social, and contextual work design features: A meta-analytic summary and theoretical extension of the work design literature. Journal of Applied Psychology, 92, 5 (2007).

10. E. L., Deci, R. M., Ryan, The "what" and "why" of goal pursuits: Human needs and the self-determination of behavior. Psychological Inquiry, 11, (2000).

11. J.K., Howard, A.N., Raymond, C. Wang, Motivation to learn and course outcomes: The impact of delivery mode, learning goal orientation, and perceived barriers and enablers, Personnel Psychology, 59, 3 (2006). 